\title{
Transcription regulation: a genomic network Nicholas Luscombe*
}

\author{
Address: European Bioinformatics Institute (EBI), EMBL Outstation, Hinxton, Cambridge, UK. \\ Email: Nicholas Luscombe* - luscombe@ebi.ac.uk \\ * Corresponding author
}

from BioSysBio: Bioinformatics and Systems Biology Conference

Edinburgh, UK, I4-15 July 2005

Published: 2I September 2005

BMC Bioinformatics 2005, 6(Suppl 3):SI

The transcriptional regulatory system plays a central role in directing gene expression changes in response to internal and external stimuli. In this talk, I will present our group's computational studies on transcription regulation in yeast, ranging from large-scale experimental studies to computational analyses of regulatory networks. In the first half I will introduce results from ChIp-chip experiments that identify genome-wide DNA-binding sites of transcription factors, particularly focusing on the cell cycle regulatory system. In the second half I will discuss how these observations fit in with the idea of a genomic regulatory network, and examine the effects of such networks on gene expression levels. Finally, I will introduce the concept of dynamic network usage in the context of transcription regulation, and how specific regulatory pathways are employed to bring about these transitions.

\section{References}

I. Luscombe NM, Babu MM, Yu H, Snyder M, Teichmann SA, Gerstein M: Genomic analysis of regulatory network dynamics. Nature in press.

2. Babu MM, Luscombe NM, Aravind L, Gerstein M, Teichmann SA: Structure and evolution of transcriptional regulatory networks. Current Opinions in Structural Biology 14:283-29I.

3. Yu H, Luscombe NM, Qian J, Gerstein M: Genome-wide analysis of gene expression relationships in transcriptional regulatory networks. Trend in Genetics 19:422-427.

4. Horak CE, Luscombe NM, Qian J, Bertone P, Piccirillo S, Gerstein M, Snyder M: Complex transcriptional circuitry at the GI/S transition in Saccharomyces cerevisiae. Genes and Development 2002, 16:3017-3033. 